\title{
Erratum to: Electrodeposition of manganese dioxide: effect of quaternary amines
}

\author{
A. Biswal • B. C. Tripathy • T. Subbaiah • D. Meyrick • \\ M. Minakshi
}

Published online: 14 April 2013

(C) Springer-Verlag Berlin Heidelberg 2013

Erratum to: J Solid State Electrochem (2013) 17:1349-1356

DOI 10.1007/s10008-013-2002-x

In the Acknowledgements section, the following lines should be added:

The authors would like to thank the Director, CSIRIMMT for his interest and encouragement in publishing this work. One of the authors AB would like to thank CSIR for providing Senior Research Fellowship for carrying out his doctoral research.

The online version of the original article can be found at http://dx.doi.org/ 10.1007/s10008-013-2002-x.

A. Biswal • B. C. Tripathy $\cdot$ T. Subbaiah

CSIR - Institute of Minerals and Materials Technology,

Bhubaneswar 751013, Odisha, India

D. Meyrick $\cdot$ M. Minakshi $(\bowtie)$

School of Chemical and Mathematical Sciences,

Murdoch University, Murdoch, WA 6150, Australia

e-mail:m.minakshi-sundaram@murdoch.edu.au

M. Minakshi

e-mail: lithiumbattery@hotmail.com 